\title{
CONFIANÇA E REPUTAÇÃO, DOCES COLONIAIS E QUEIJO SERRANO: PERCEPÇÕES DE QUALIDADE DE ALIMENTOS TRADICIONAIS EM CONTEXTOS DE PROXIMIDADE ENTRE AGRICULTORES E CONSUMIDORES
}

Evander Eloí Krone (1)

Renata Menasche (D)

Universidade Federal de Pelotas I Pelotas - RS - Brasil 
Este artigo parte da observação das tendências da alimentação contemporânea que vêm apontando para movimentos de valorização de produtos tradicionais. Buscamos, aqui, compreender de que modo a confiança é acionada em contextos marcados pela informalidade e por relações de proximidade entre produtores e consumidores de alimentos. Nossa atenção é dirigida a dois casos referentes a produtos artesanais, o do Queijo Serrano, produzido na região dos Campos de Cima da Serra, e o dos doces de frutas da região de Pelotas, ambas localizadas no estado do Rio Grande do Sul. O estudo, de caráter etnográfico, buscou analisar os pontos de vista das famílias rurais produtoras desses alimentos, que estão inseridas em canais curtos de comercialização. A observação dos contextos estudados evidenciou percepções acerca da qualidade dos produtos pautadas em relações de confiança e reputação dos produtores e, desse modo, conformadas localmente, a partir de parâmetros socialmente construídos.

Palavras-chave: antropologia da alimentação; confiança; produtos tradicionais; consumo.

\section{TRUST AND REPUTATION, COLONIAL SWEETS AND SERRANO CHEESE: PERCEPTIONS OF TRADITIONAL FOOD QUALITY IN PROXIMITY CONTEXTS BETWEEN FARMERS AND CONSUMERS}

This paper starts from the observation of the contemporary food trends that have been pointing to movements of valorization of traditional products. We seek in this paper to understand how the trust is triggered in contexts marked by informality and proximity relations between food producers and consumers. Our attention is directed to two cases related to artisanal products, the Serrano Cheese produced in the Campos de Cima da Serra region, and the fruit jams from Pelotas region, both located in the State of Rio Grande do Sul. The ethnographic study sought to analyze the points of view of the rural families producing these foods, which are inserted in short marketing channels. The observation of the studied contexts evidenced perceptions about the quality of the products based on relations of trust and reputation of the producers and, thus, locally conformed, from socially constructed parameters.

Keywords: anthropology of food; trust; traditional products; consumption.

\section{CONFIANZA Y REPUTACIÓN, DULCES COLONIALES Y QUESO SERRANO: PERCEPCIONES DE LA CALIDAD DE ALIMENTOS TRADICIONALES EN CONTEXTOS DE PROXIMIDAD ENTRE AGRICULTORES Y CONSUMIDORES}

Este trabajo parte de la observación de las tendencias alimentarias contemporáneas que apuntan a movimientos de valorización de los productos tradicionales. Buscamos comprender de qué modo la confianza es accionada en contextos marcados por la informalidad y por relaciones de proximidad entre productores y consumidores de alimentos. Analizamos dos casos referentes a productos artesanales, el del Queso Serrano, producido en la región de los Campos de Cima da Serra, y el de los dulces de frutas de la región de Pelotas, ambas ubicadas en el Estado de Rio Grande do Sul. Este estudio etnográfico buscó analizar los puntos de vista de las familias rurales productoras de esos alimentos, que están insertas en canales cortos de comercialización. El estudio evidenció percepciones acerca de la calidad de los productos pautados en relaciones de confianza y reputación de los productores y, de ese modo, conformadas localmente, a partir de parámetros socialmente construidos.

Palabras clave: antropología de la alimentación: 


\section{INTRODUÇÃO}

Dado o marco em que se observam, na atualidade, práticas de valorização de produtos locais, artesanais e tradicionais, este artigo busca refletir a respeito dos significados da confiança em contextos marcados por relações de proximidade entre produtores e consumidores.

Comer é um ato corriqueiro, porém tal ação traz consequências que podem ser irreversíveis para a vida humana. Do ponto de vista biológico, o alimento ingerido é absorvido pelo corpo, e suas propriedades bioquímicas podem gerar a energia que torna possível a continuidade da vida ou mesmo, em caso de o alimento ingerido estar contaminado, podem levar à morte. Confiança é, assim, elemento central que permeia a relação dos humanos com sua alimentação.

Desde o século XIX, o mundo vem experimentando um processo de intensificação da globalização da cadeia agroalimentar e de ampliação da separação entre produtores e consumidores. Autores como Friedmann \& McMichael (1989) argumentam que as dietas alimentares que tiveram lugar durante os séculos XIX e XX resultaram em três diferentes regimes alimentares globais. O primeiro deles, influenciado pelo domínio britânico - do final do século XIX até a Segunda Guerra Mundial -, foi essencialmente marcado pela importação europeia de gêneros alimentícios dos territórios invadidos pela colonização europeia. No pós-guerra, o Estado passou a controlar as relações de produção e comercialização, levando ao surgimento de um segundo regime alimentar global, influenciado pelo modelo fordista americano de produção em massa. Para os autores citados, um terceiro regime se estabelece a partir da década de 1980 , baseado no modelo neoliberal, que corresponde à situação atual de globalização dos mercados agroalimentares.

Mintz (1986) lembra que há poucos séculos a ampla maioria dos alimentos era obtida localmente, sendo produzida pelas próprias pessoas, em pequenas unidades agrícolas. Desse modo, os alimentos básicos da dieta não eram deslocados para áreas muito distantes do local original de sua produção. Na atualidade, no entanto, eles atravessam fronteiras continentais, e a confiança, antes mediada por relações de proximidade entre consumidores e produtores, em boa medida cedeu lugar a um aparato complexo, constituído por especialistas, empresas certificadoras, laboratórios e agentes do Estado, que procuram fiscalizar e conferir segurança ao sistema de produção de alimentos. A qualidade deles jamais foi tão vigiada e controlada, como tem sido nas sociedades contemporâneas, buscando garantir - ao menos na opinião dos especialistas - alimentos mais seguros. No entanto, o consumidor parece experimentar, mais do que nunca, desconfiança em relação à alimentação.

Contreras (2005) ressalta que, atualmente, os consumidores reconhecem apenas os 
elementos terminais presentes nas prateleiras dos supermercados, enquanto o restante do complexo sistema agroalimentar é uma espécie de caixa-preta, que provoca medo e desconfiança. A indústria agroalimentar, influenciada pelos movimentos mais gerais da globalização, promoveu o rompimento entre os alimentos e o seu universo social de produção, razão pela qual, segundo Contreras \& Gracia (2011), esses produtos não se encontram adequadamente adaptados nas representações e na cultura dos consumidores. Parcela significativa da população consome algo que foi produzido totalmente fora do alcance de seus olhos, isto é, produtos sem história nem memória social (Fischler 1995). Uma vez que boa parte das atividades culinárias passou para as mãos da indústria, o alimento moderno perdeu sua capacidade mediadora e converteu-se "em um artefato misterioso, [...] um objeto comestível não identificado, sem passado nem origem conhecidos" (Fischler 1995:210).

É nesse quadro que as sucessivas crises e os escândalos protagonizados pela indústria agroalimentar têm minado a confiança no setor. Ademais, o desconhecimento em relação a efeitos de agentes químicos utilizados na produção alimentícia e as incertezas e rumores em relação a métodos industriais utilizados nesse processo contribuem para despertar a desconfiança em relação à qualidade do que é oferecido ao consumidores, cujas origens encontram-se distanciadas dos contextos vivenciados pela população consumidora.

Ao refletir sobre as ansiedades urbanas contemporâneas em relação à alimentação, Fischler (1995) argumenta que, diferentemente do que faziam seus antepassados, o comensal moderno perdeu referências no momento de realizar suas escolhas neste âmbito, isso devido a uma cacofonia alimentar, que identifica como característica da sociedade moderna, quadro em que as advertências sobre riscos amplificam-se na mesma medida em que aumentam conflitos e discórdias entre especialistas e cientistas sobre modelos de consumo, contribuindo para o estado de confusão e criando ambiente propício à proliferação de rumores a respeito da indústria agroalimentar. Contreras \& Gracia (2011) acrescentam que, nestes sistemas hipercomplexos, os consumidores, cada vez mais desorientados, escutam todo tipo de rumores lançados por uma imprensa sensacionalista, o que contribui para a construção de incertezas em torno da produção alimentar, daí as pressões que atuam sobre o consumidor contemporâneo.

É nesse contexto que atributos associados à produção local e de origem conhecida têm se sobressaído na demanda por alimentos que enfatizam qualidades como tradição, localidade, ruralidade, aspectos naturais e ausência de produtos químicos. Seguramente, a crise de confiança na indústria agroalimentar tem aberto espaço para a valorização de produtos locais, tradicionais e 
artesanais, também alavancando o comércio direto entre produtores e consumidores.

Nesse sentido, este artigo se propõe a apreender de que modo a confiança é acionada e operada em contextos marcados pela informalidade e por relações de proximidade entre produtores e consumidores de alimentos. Para esta reflexão, tomamos dois casos referentes a produtos artesanais, de distintas regiões do Rio Grande do Sul (Figura 1): o Queijo Serrano, produzido nos
Campos de Cima da Serra ${ }^{1}$, e os doces de frutas da região de Pelotas², no extremo sul gaúcho.

Cabe destacar que, em maio de 2018, o IPHAN concedeu às tradições doceiras ${ }^{3}$ de Pelotas o título de patrimônio cultural do Brasil. Já o Queijo Serrano está em processo de reconhecimento, dado que o dossiê solicitando o seu registro como patrimônio cultural foi entregue ao IPHAN e aguarda a realização de pesquisa de campo e outros levantamentos.

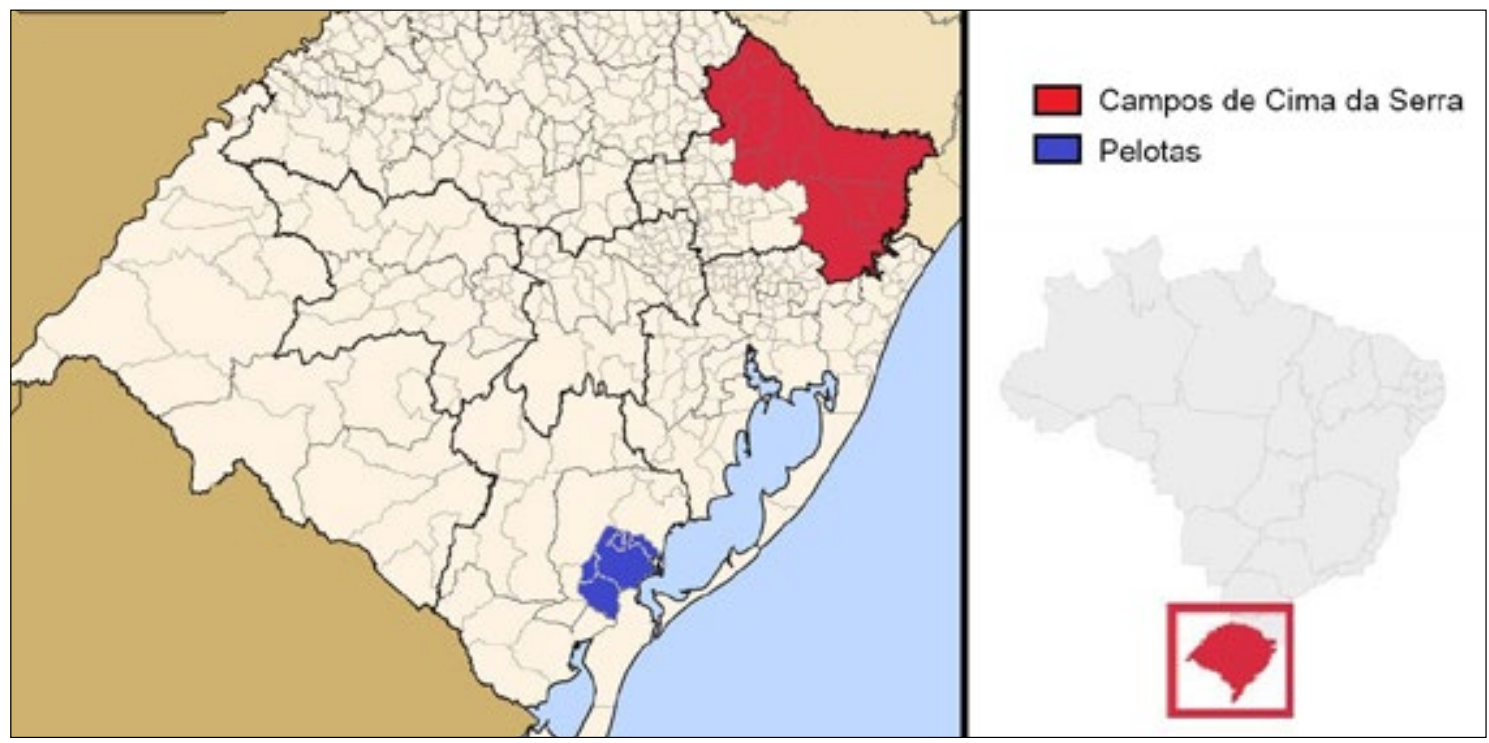

Figura 1 - Mapa ilustrativo situando as regiões pesquisadas. Fonte: adaptado de Wikipédia (2019).

1 Tomando como referência a unidade da microrregião de Vacaria, conforme a divisão utilizada pelo Instituto Brasileiro de Geografia e Estatística (IBGE), a região dos Campos de Cima da Serra é composta por quatorze municípios: Bom Jesus, Cambará do Sul, Campestre da Serra, Capão Bonito do Sul, Esmeralda, Ipê, Jaquirana, Lagoa Vermelha, Monte Alegre dos Campos, Muitos Capões, Pinhal da Serra, São Francisco de Paula, São José dos Ausentes e Vacaria.

2 A região doceira, como reconhecida pelo Instituto do Patrimônio Histórico e Artístico Nacional (IPHAN), é composta pelos seguintes municípios: Pelotas, Arroio do Padre, Capão do Leão, Morro Redondo e Turuçu.

3 São duas as tradições doceiras reconhecidas como patrimônio pelo IPHAN: a tradição dos doces finos e a dos doces coloniais. A dos doces finos é atribuída à colonização portuguesa desta região, e concentrou-se, sobretudo, na área geográfica da planície costeira próxima à lagoa dos Patos e, particularmente, na sede urbana do atual município de Pelotas. Já a dos doces coloniais surgiu associada às propriedades dos colonos de origem europeia que chegaram à região a partir da segunda metade do século XIX. 
Dessa forma, este estudo está também inserido nesse esforço, empreendido por um conjunto de entidades da sociedade civil para o reconhecimento e a proteção desses produtos como patrimônio cultural.

Nesse sentido, este estudo, de caráter etnográfico, buscou analisar os pontos de vista das famílias rurais produtoras desses alimentos tradicionais, que estão inseridas em canais curtos de comercialização. As reflexões aqui desenvolvidas têm origem em iniciativas de pesquisas realizadas em períodos distintos. No nordeste gaúcho, o contexto das famílias rurais produtoras artesanais de Queijo Serrano foi alvo de pesquisa entre 2006 e 2009 (Krone 2006, 2009). Em Pelotas, a observação do modo de vida das famílias rurais produtoras de doces de frutas foi realizada entre 2014 e 2018 (Krone 2018).

A orientação metodológica que pautou as incursões a campo está ancorada na tradição do método etnográfico. A pesquisa a campo se deu, desse modo, a partir da inserção junto aos grupos sociais estudados. Partindo da ideia do contato como fundadora da relação etnográfica entre interlocutor e pesquisador, buscou-se construir uma interação prolongada com os sujeitos estudados, de modo a acessar seus círculos sociais e formas de pensamento. Nesses termos, procurou-se realizar o trabalho interpretativo do discurso social a partir da aproximação ao ponto de vista nativo (Geertz 1989).

Foi assim que se procedeu à gravação de entrevistas semiestruturadas, método complementar ao procedimento de observação participante. No total, foram entrevistadas e estudadas 32 famílias rurais, sendo 17 localizadas nos Campos de Cima da Serra e 15 em Pelotas. Paralelamente, os dados obtidos em situações e conversas informais com os interlocutores foram registrados com uso de diário de campo e com emprego de recursos imagéticos. Posteriormente, esses dados foram sistematizados com o suporte de softwares. As entrevistas foram transcritas com o auxílio do programa Transcriber ${ }^{4}$, o que garantiu a transformação do áudio em texto. Já a organização material dos arquivos digitais (entrevistas e obras bibliográficas) foi realizada com o apoio do programa Mendeley, o que permitiu armazenar, gerenciar, editar e adicionar notas aos arquivos digitais, facilitando, assim, o processo de categorização e análise do material.

4 Para mais informações, ver http://transag.sourceforge.net/.

5 Para mais informações, ver https://www.mendeley.com/. 
Nos tópicos 2 e 3 do artigo, apresentamos os dois contextos empíricos estudados: primeiramente, abordamos os processos de produção e comercialização do Queijo Serrano, evidenciando as relações de proximidade entre famílias produtoras e consumidores; na seção seguinte, ao analisar o universo da produção dos doces coloniais de Pelotas, buscamos iluminar o modo como são estabelecidas as relações de proximidade e confiança que possibilitam a circulação da produção doceira entre famílias produtoras e consumidores urbanos. No tópico 4, buscamos analisar a maneira como as informações socialmente produzidas e compartilhadas sobre as reputações das famílias produtoras, construídas em relações face a face, convertem-se em elemento que garante confiança no âmbito de circuitos curtos de comercialização, sobrepondose, em relevância, aos aspectos legais pertinentes à produção de alimentos.

\section{QUALIDADE E CONFIANÇA NO CONSUMO DO QUEIJO SERRANO}

A região dos Campos de Cima da Serra tem na pecuária de corte em sistema de campo nativo uma de suas principais atividades econômicas. Associada à bovinocultura de corte, desenvolveuse a produção artesanal de um queijo característico, conhecido localmente como Queijo Serrano, cuja receita remonta ao século XVIII.

Essa receita foi passada de geração a geração, de modo que o saber-fazer desse queijo perpetuouse ao longo do tempo, sem sofrer modificações significativas. O microclima próprio da região, combinado às técnicas artesanais empregadas na fabricação do queijo - com a utilização de leite cru de vacas de corte, alimentadas a partir de pastagens naturais fornecidas pelos campos nativos -, confere ao produto características físicas e organolépticas únicas, que lhe dão especificidade e o diferenciam de outros queijos.

O Queijo Serrano é importante fonte de renda para as famílias produtoras, que adquirem grande parte de seu sustento a partir do que ganham com a venda do produto. Esse produto é vendido principalmente para consumidores locais, pequenos estabelecimentos comerciais ou atravessadores, que vendem a produção em municípios da região.

No entanto, apesar de toda importância econômica, histórica e cultural, a comercialização do Queijo Serrano se realiza à margem de canais formais de comercialização. As famílias rurais produtoras vivem sob a ameaça de multas e apreensão dos produtos, uma vez que os processos de produção do queijo são considerados inadequados pela legislação sanitária, sendo uma das principais polêmicas 
referente ao fato de que as famílias utilizam leite cru durante o preparo desse queijo.

Cabe abrir parênteses para explicar que, no final da década de 1940, nos Estados Unidos, o Food and Drug Administration (FDA) ${ }^{6}$ determinou que queijos produzidos a partir de leite cru apenas fossem comercializados após prazo mínimo de 60 dias de maturação. A norma estabelecida pelo FDA influenciou vários outros países, inclusive o Brasil, que adotou o mesmo parâmetro. Ainda, desde os anos 1990, o Codex Alimentarius ${ }^{7}$ vem recomendando a pasteurização dos produtos de origem láctea, alegando riscos no consumo de produtos derivados de leite cru. No entanto, defensores dos queijos preparados a partir de leite cru criticam a arbitrariedade e a falta de transparência no estabelecimento do prazo mínimo de 60 dias de maturação. Estudos como os de Cruz (2012) e Cruz \& Menasche (2014) apontam a inexistência de evidências científicas consistentes que sustentem esse critério.

$\mathrm{Na}$ Europa, particularmente em países como a França, onde o preparo de queijos a partir de leite cru tem larga tradição, ativistas e movimentos sociais vêm lutando na defesa dos métodos tradicionais neste tipo de produção. Bérard \& Marchenay (2004 apud Cruz 2012) alertam para o fato de os americanos conformarem a maioria dos integrantes do Codex Alimentarius e representantes de indústrias dos Estados Unidos possuírem membros nos comitês relativos às normatizações, indicando que, muito além de questões sanitárias, o que está em jogo é o poder de regulamentar o mercado.

Nesse sentido, como mostram Schottz et al. (2014), as avaliações e decisões a respeito dos riscos sanitários estão se movendo progressivamente para os circuitos internacionais, situação que reverbera no enfraquecimento da soberania e da democracia dos Estados nacionais, especialmente nos países em desenvolvimento. Desse modo, as regras ditadas internacionalmente - moldadas por e para o modelo agroindustrial de produção - são frequentemente referendadas pelas legislações nacionais, acabando por constituir-se em constrangimento à existência de modos de produção artesanais, que são a base de muitas

6Órgão que regulamenta e normatiza as legislações sobre medicamentos e produção de alimentos nos Estados Unidos.

7 Comissão criada pela Organização das Nações Unidas para Alimentação e Agricultura (FAO) e constituída por vários países para estabelecer padrões e guias internacionais, tanto no que se refere, por exemplo, à ingestão máxima aceitável e/ou recomendável de algum aditivo alimentar, quanto para determinar parâmetros e riscos microbiológicos dos alimentos. 
culturas alimentares locais (Dias et al. 2018). Seguramente, a união entre Estado, indústria e ciência reverberou na constituição de um imenso emaranhado institucional, bem como no desenvolvimento de parâmetros de qualidade que desencadearam a formação de leis e normas sanitárias, as quais permitiram aumentar o controle sobre a produção de alimentos. Porém, como demostram trabalhos como os de Schottz et al. (2014), Cintrão (2016), Krone (2018), entre outros, as leis e regras sanitárias estão longe de ser neutras e baseadas unicamente em critérios científicos, uma vez que as disputas em torno de regras sanitárias escondem, frequentemente, agendas políticas e econômicas que visam favorecer determinados setores da indústria.

No caso específico do Queijo Serrano, consumidores, produtores, técnicos e comerciantes da região estudada concordam que, para que um queijo seja considerado Serrano, é condição a utilização de leite cru em sua produção. E, de um modo geral, os moradores da região preferem consumir este queijo com 15 a 20 dias de maturação. Para os agentes locais, alterar essa característica implicaria perda de qualidade, de sabor e de propriedades únicas do produto. Assim, os critérios empregados por produtores e consumidores da região a respeito do tempo adequado de maturação diferem significativamente dos 60 dias requeridos pela legislação brasileira.

Ainda, os requisitos para legalização do Queijo Serrano envolvem consideráveis investimentos em infraestrutura, bem como na substituição de utensílios tradicionais, como formas, pás e barris de madeira ${ }^{8}$, comumente usados na região. Os utensílios de madeira são considerados inadequados pela fiscalização sanitária, que pressiona as famílias produtoras a adotar materiais como inox e polietileno, além de exigir investimentos significativos na adequação das instalações. Dados os elevados custos envolvidos, somados ao fato de que tais adequações às normas descaracterizam o produto tradicional, boa parte das famílias optam por manter sua produção na informalidade. Dessa forma, assim como ocorre com muitos outros produtos tradicionais brasileiros comercializados à margem da legalidade, o Queijo Serrano é comumente vendido sem qualquer rótulo ou selo que identifique sua procedência (Figura 2).

8 A despeito da visão higienista hegemônica de que a madeira é uma ameaça à qualidade dos alimentos, vários estudos têm apontado no sentido contrário, ressaltando os seus benefícios nesse processo. Particularmente, na produção de queijos e vinhos, o tipo de madeira utilizado pode acrescentar atributos positivos ao paladar e à qualidade dos produtos (E. Ferreira \& C. Ferreira 2011; Lortal et al. 2009). 

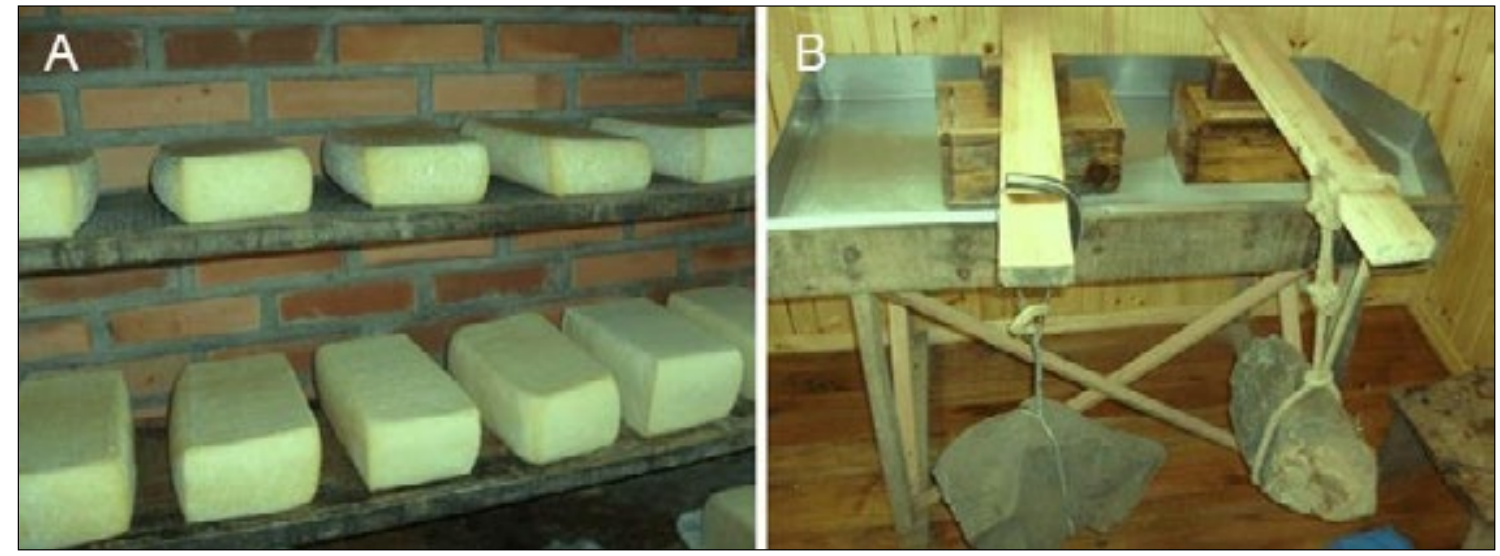

Figura 2 - Queijo Serrano: A) queijo sendo maturado; B) etapa de prensagem do queijo com o uso de pedras. Fotos: E. E. Krone (2008).

No entanto, ainda que este tipo de produção artesanal não obedeça às normas legais estabelecidas pelo Estado, isso não parece ser um problema para os consumidores da região, que têm clareza a respeito dos métodos tradicionais de produção desse queijo, os quais não seguem os requisitos definidos em lei, de modo que a maior parte das famílias produtoras, como dito, atua na informalidade. No contexto local, os requisitos legais parecem ser menos importantes para os consumidores do que os critérios socialmente estabelecidos para avaliar a qualidade dos queijos. Nesse sentido, as escolhas e preferências de consumo são definidas, em grande medida, em razão de um conhecimento socialmente produzido e compartilhado a respeito da qualidade dos queijos e da reputação dos produtores. Nesse sentido, aspectos como confiança e reputação conformam um critério de outro tipo e tornam-se significativos na relação direta entre produtor e consumidor.

O Queijo Serrano tem como uma de suas principais características o processo artesanal de fabricação. Ao contrário das tecnologias mecânicas, que tendem, através de repetições infindáveis, a padronizar produtos e processos, a artesanalidade é baseada na contínua habilidade humana de criar e inovar (Ploeg 2008). O processo de produção do Queijo Serrano é resultado, então, da diversidade do saber-fazer local, sendo que o preparo artesanal, neste caso, difere significativamente dos processos industriais de produção de alimentos da moderna indústria agroalimentar, em que o que prevalece não é a diversidade, mas processos que visam ter a padronização como resultado final. Por isso, é possível afirmar que, justamente devido a este processo artesanal, realizado em pequena escala e por várias famílias rurais, cada produtor atua como um artesão, imprimindo no queijo que 
elabora características únicas.

Essa diversidade de modos de fazer se reflete, por exemplo, no fato de serem encontrados no comércio local queijos com características muito distintas. É assim que o consumidor tem à disposição desde produtos com pouco sal até aqueles em que o sabor salgado é bastante acentuado. Ainda, o Queijo Serrano é costumeiramente vendido em diferentes formatos e tamanhos, assim como há diferenças entre os mais ou menos maduros, ou seja, essa diversidade de modos de fazer resulta em um conjunto de queijos com texturas, cores, aromas e sabores muito diversos.

Por isso, ainda que os queijos vendidos não tenham rótulo ou selo que identifique sua procedência, essa diversidade de formatos, texturas e sabores auxilia os consumidores na identificação dos produtores. Desse modo, as características específicas desses produtos são geralmente associadas ao saber-fazer do queijeiro responsável por sua produção. É isso o que afirma Seu Camilo?, produtor de Queijo Serrano:

\section{E no tempo que eu vendia queijo no armazém em Bom Jesus [município], tinha uma mulher lá de Lageado [distrito do município de São Francisco de Paula], que chegou ali. Eu estava ali com um conhecido}

e com o açougueiro, por ali, conversando, e uma hora ela pediu: "Eu queria o queijo do seu Camilo". É esse daqui, está falando com ele. Pensa bem, a mulher de lá, ela sabia que eu fazia queijo. Onde que ela iria imaginar que era eu? Estava lá, comprando queijo. Ela já conhecia o meu queijo.É que o pessoal vai se habituando. Então a gente já sabe, se tu chega lá onde eu vendo o meu queijo, eles te dizem bem certinho, esse aqui é o fulano que faz. Tem uns parecidos, mas igual não tem.

A relação direta ou muito próxima entre consumidores e produtores de Queijo Serrano favorece a referência ao nome do produtor, o que permite apontar que existe forte associação entre a reputação do produtor, o queijo produzido e a qualidade específica do produto. E, como evidenciado pela fala de Seu Camilo, esse conhecimento socialmente produzido sobre a reputação dos produtores se difunde pela região, entre consumidores com quem as famílias produtoras não possuem contato direto.

De fato, como mostra o trabalho de Cruz et al. (2014), realizado junto a produtores e consumidores de Queijo Serrano, nomes de bons produtores de queijo surgem, muitas vezes, espontaneamente em conversas informais. Desse modo, é possível afirmar que existe um conhecimento socialmente compartilhado entre

9 Ao refletir sobre a utilização de nomes verdadeiros ou fictícios no texto etnográfico, Fonseca (2007) argumenta que o uso do anonimato nem sempre é sinal de respeito para com os interlocutores, pois, de certo modo, acaba mascarando a identidade dos sujeitos, como se fossem infratores. Neste artigo, várias das situações relatadas poderiam expor as famílias rurais produtoras, uma vez que elas vivem sob constante ameaça de multas e apreensão de seus produtos, razão pela qual optamos pelo uso de nomes fictícios, de modo a preservar a identidade e a integridade dos interlocutores da pesquisa. 
os moradores da região, uma vez que, quando questionados, os consumidores da região costumam sugerir locais onde se pode adquirir o produto e indicar aqueles que são considerados os bons produtores de Queijo Serrano.

Prigent-Simonin \& Hérault-Fournier (2005), em pesquisa que analisa a influência da relação consumidor-produtor na percepção da qualidade dos alimentos, argumentam que os critérios de julgamento nesse âmbito podem variar quando há relação de proximidade entre produtores e consumidores. As autoras defendem a ideia de que o componente relacional influencia no processo de avaliação dos produtos, de modo que a percepção da qualidade está intimamente associada aos componentes de confiança que emergem da relação de proximidade. É assim, por exemplo, no caso do Queijo Serrano, em que as características únicas do produto, associadas à reputação de cada produtor, são elementos fundamentais que orientam as práticas de consumo e de avaliação da qualidade dos queijos comercializados. Nesse sentido, a presença de rótulos ou selos nos produtos tem menos importância do que as reputações dos produtores, que circulam entre os agentes presentes nas redes curtas de comercialização.
Vejamos, a seguir, o que mostra, sobre o tema, o outro contexto empírico analisado nesta pesquisa, em que interagem consumidores e produtores de doces de frutas de Pelotas.

\section{PROXIMIDADE E CONFIANÇA NO CONSUMO DOS DOCES COLONIAIS}

Na região de Pelotas, a partir de uma política pública de povoamento que resultou em uma agricultura camponesa policultora, o Estado promoveu, a partir de 1858, a vinda de imigrantes europeus de diversas origens, especialmente alemães, franceses, italianos, poloneses e pomeranos. Esses imigrantes foram instalados em colônias agrícolas da região, razão pela qual passaram a ser conhecidos como colonos. Entre seus cultivos, desde os primeiros tempos estiveram presentes frutas como figo, goiaba, laranja, pêssego e uva, que viriam a ser aproveitadas na formação de uma indústria artesanal de produção de doces de frutas (Figura 3).

Nessa produção, os principais ingredientes são frutas de época, geralmente cozidas apenas com água e açúcar, resultando em geleias, Schmiers ${ }^{10}$, cristalizados, doces em passa, entre outros. Tal produção conformou uma tradição doceira, conhecida como doces coloniais, doces de fruta,

10 Entre os colonos do Sul do Brasil, Schmier é o doce pastoso utilizado para passar no pão. A palavra Schmier deriva do verbo Schmieren, que, em alemão, significa untar. A Schmier é elaborada a partir da polpa de frutas, que são descascadas, picadas ou trituradas e, posteriormente, cozidas com água e açúcar. 

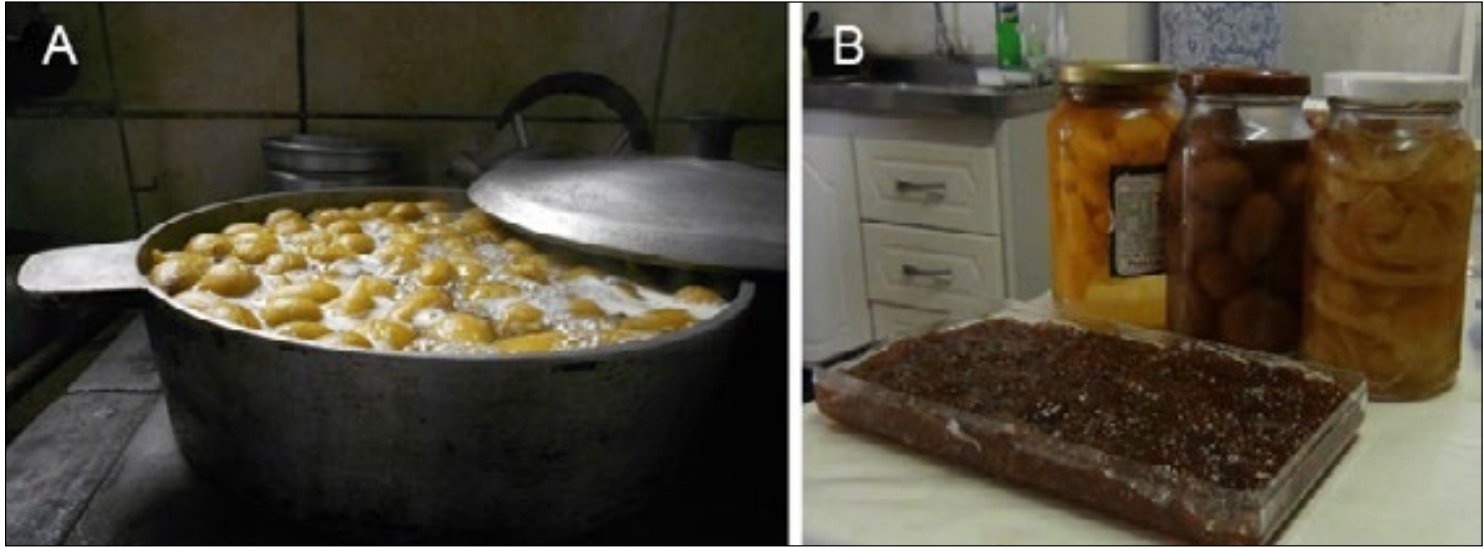

Figura 3 - Produção de doces coloniais: A) doce de figo sendo preparado sobre o fogão a lenha; B) doces de figo, laranja e pêssego em pasta e calda. Fotos: E. E. Krone (2016).

doces de safra e, eventualmente, doces de tacho, visto que muitos destes são costumeiramente produzidos em tachos de cobre.

Desse modo, a prática de produção de doces de frutas se constitui como tradição mantida por famílias rurais há pelos menos 150 anos, sendo atividade intimamente associada ao modo de vida e à identidade dos moradores da região. Não obstante sua importância nas esferas econômica e cultural, essa tradição vive sob a tensão decorrente da ação de órgãos de fiscalização sanitária do Estado.

A produção de doces coloniais é habitualmente mantida por famílias rurais, em pequenas fábricas de doces ou em cozinhas domésticas, onde são elaborados no fogão a lenha ou a gás, ou mesmo no pátio de casa, frequentemente com emprego de tachos de cobre, pás e colheres de madeiras, utensílios atualmente proibidos pelos órgãos de fiscalização sanitária.
Nas pequenas fábricas de doces da região, o modo artesanal de feitura dos doces foi, em boa medida, substituído por métodos semi-industriais de produção. Para legalizar a venda desses produtos, as famílias rurais viram-se obrigadas a substituir antigos utensílios e equipamentos, como tachos de cobres, pás e colheres de madeira, que passaram a dar lugar a outros utensílios, geralmente mais onerosos e de origem industrial. Assim, por meio dos órgãos de vigilância sanitária, o Estado busca disciplinar a produção de doces coloniais a partir de parâmetros da indústria agroalimentar.

Não por acaso, nas últimas décadas, com o recrudescimento da legislação sanitária e a decorrente necessidade de investimentos para adequar a produção à matriz industrial, tudo isso somado à ocorrência de sucessivas crises econômicas, tem ocorrido, na região de Pelotas, a desativação de muitas fábricas de doces ou o deslocamento de produtores à informalidade. 
Pode-se considerar que, na região, as fábricas de doces regularizadas constituem-se em exceções. Estimase que a produção de doces coloniais movimente a vida de cerca de cinco mil famílias rurais da região, sendo que a maior parte delas realiza a atividade na informalidade (Santos \& Gonçalves 2010), sob risco de multas e apreensões. É nesse contexto, buscando comercializar sua produção à margem dos controles estatais, que as famílias rurais produtoras de doces acionam suas redes de sociabilidade.

A associação entre produção doceira e identidade local parece fortalecer práticas de resistência das famílias rurais, uma vez que o consumo de doces artesanais está culturalmente enraizado tanto na vida de produtores quanto na de consumidores urbanos, que demandam o produto. Assim, da mesma forma que ocorre com o Queijo Serrano, também em Pelotas os consumidores são cientes de que a produção doceira local não é realizada de acordo com os parâmetros estabelecidos pela vigilância sanitária e que, em boa medida, se dá na informalidade. É nesse quadro que a circulação dos doces coloniais ocorre principalmente através de redes de reciprocidade, parentesco e amizade, revelando a existência de um circuito informal de comercialização, que aproxima agricultores e consumidores urbanos. É através desse circuito que consumidores buscam ter acesso a doces com as qualidades socialmente valorizadas, ainda que não atendam aos parâmetros de qualidade impostos pela vigilância sanitária.
Uma das formas mais comuns de venda de doces encontrada pelas famílias rurais é alicerçada na mediação realizada por filhos ou outros parentes que moram na cidade. Na atualidade, muitas famílias rurais possuem filhos estudando ou trabalhando na sede do município de Pelotas. É comum que, aos finais de semana, esses moradores da cidade desloquem-se para a casa dos pais, na zona rural. Quando retornam à cidade, levam consigo doces, que são vendidos a colegas e amigos. Essa venda se constitui em fonte de renda para as famílias rurais, muitas vezes destinada à manutenção dos filhos na cidade, onde estudam.

Assim, esses filhos são importante elo entre famílias produtoras de doces e consumidores urbanos. Mas, é claro, nem todas as famílias rurais têm filhos ou parentes morando na cidade de Pelotas. Vale, então, lançar luz sobre outra prática bastante comum, presente entre as famílias rurais: o envio de encomendas de doces por meio dos ônibus da colônia. Vejamos como Dona Aline, produtora de doces coloniais, descreve essa prática:

\section{Aline: Viu a minha beira da estrada lá? Tá capinada, lá onde se espera o ônibus, [...] pra botar umas caixas de doce, que às vezes o pessoal me faz o pedido, aí então eu pego e mando pelo ônibus.}

Evander: Ah, manda pelo ônibus?

Aline: Os rapazes [cobrador e motorista] do ônibus levam. Aí a pessoa espera já lá na cidade, porque assim a pessoa fez o pedido, então depois eu boto no ônibus e a pessoa pega lá em Pelotas. 
Há, em Pelotas, diversas empresas que realizam o transporte público no meio rural, sendo que vários terminais de ônibus que ligam a cidade às comunidades rurais estão localizados em distintos pontos da cidade. Conforme explicou Dona Aline, quando a encomenda é enviada pelo ônibus, é combinado com o cliente o horário de recebimento, bem como o terminal ou parada de ônibus em que ele deverá esperar. O pagamento da encomenda é realizado para o pai de Dona Aline, que mora em Pelotas, ou por meio de depósito bancário. Vale ainda mencionar ser comum, em agradecimento, motoristas e cobradores serem presenteados pelos produtores com caixas de doces.

Eventualmente, os próprios agricultores realizam a entrega de doces na cidade. Quando não possuem carro próprio, costumam transportar seu produto em ônibus, os mesmos que fazem a ligação da zona rural com a cidade. É o caso de Dona Lorena, agricultora com quem tivemos oportunidade de conversar durante uma das viagens em ônibus realizadas para a zona rural da região. Dona Lorena relatou que, tendo ficado viúva e precisando cuidar de seu filho pequeno, passou a fazer Schmiers e compotas para vender. No dia em que se realizou essa conversa, Dona Lorena levava seu filho, de um ano de idade, para uma consulta médica e transportava consigo duas sacolas de doces, que haviam sido encomendados por conhecidos e familiares. Chegando ao terminal de ônibus, na cidade, Dona Lorena aninhou o filho junto ao seu corpo, no "canguru" (carregador para bebês), deixando as mãos livres para carregar as duas sacolas de doces, que seriam entregues nas residências de seus clientes.

Assim, a pesquisa realizada em Pelotas mostrou que os consumidores de doces coloniais são, comumente, pessoas próximas das famílias produtoras ou de seus parentes, sendo que muitos são ex-moradores da zona rural, os quais buscam doces com a qualidade daqueles que costumavam consumir quando lá viviam. É nesse quadro que os consumidores urbanos são como que cúmplices das ações desviacionistas das famílias produtoras, que precisam burlar as redes de vigilância do Estado para assegurar a viabilidade do comércio de doces produzidos de forma tradicional.

Por tal motivo, é essencial manter uma boa reputação no interior desse círculo de comercialização, em que praticamente todos se conhecem, pois, como evidenciado pela fala de Seu Jairo - um produtor de doces de Pelotas -, o produtor que é considerado "desonesto, usa fruta meio estragada, se é meio sujo, relaxado, todo mundo já fica sabendo e a pessoa fica mal falada, aí esse cara já tá condenado na comunidade". Nesse contexto, a confiança nos produtores de doces é constituída em relações face a face, a partir de informações sobre 
suas reputações, que circulam entre consumidores. Assim é que as famílias rurais produtoras de doces são permanentemente objeto de comentários e avaliações, que podem acentuar, ou mesmo refutar, a confiança na qualidade desses produtos.

\section{4. "O MEU RÓTULO É A MINHA CARA":}

\section{A VALIDAÇÃO SOCIAL DA QUALIDADE DE ALIMENTOS TRADICIONAIS}

Em trabalho que examina a construção da confiança em feiras certificadas de produtores orgânicos do estado do Rio de Janeiro, Portilho \& Castañeda (2011) demonstram como mecanismos reguladores convencionais, a exemplo de selos de empresas certificadoras, são fonte de desconfiança para os consumidores. Os autores evidenciam que os consumidores confiam mais nas relações face a face, sustentadas no contato direto e no interconhecimento mútuo com os feirantes do que em mecanismos reguladores de empresas certificadoras. As conclusões apresentadas pelos autores corroboram as evidências encontradas nos Campos de Cima da Serra e em Pelotas, uma vez que o não cumprimento das exigências legais que envolvem a produção artesanal de Queijo Serrano e de doces coloniais não parece ser um fator determinante nas práticas de consumo dos moradores das regiões estudadas. Critérios como confiança e reputação dos produtores emergem como formas de validação social da qualidade dos produtos, sobrepondo-se aos mecanismos legais de controle do Estado. Nesses contextos, em que há contato entre quem consome e quem produz, a confiança é especialmente avalizada pelas relações sociais e redes de conhecimento, que conectam produtores e consumidores, bem como endossam a percepção de qualidade dos alimentos.

Ao refletir sobre risco na contemporaneidade, Giddens (1991) aponta que, em sociedades tradicionais, a confiança é permeada por "compromissos com rosto", isto é, inserida em relações sociais mantidas e expressas em situação de copresença, enquanto que, em sociedades industriais contemporâneas, a confiança seria mediada por "compromissos sem rosto", dado estar alicerçada em sistemas abstratos de conhecimento. $\mathrm{O}$ autor argumenta, ainda, que o funcionamento desses sistemas abstratos - embasados em conhecimentos peritos - é desconhecido para os indivíduos leigos.

Dessa forma, Giddens (1991:35) compreende os sistemas peritos como "sistemas de excelência técnica ou competência profissional que organizam grandes áreas dos ambientes material e social em que vivemos hoje”. No mundo contemporâneo, as populações humanas encontram-se, todo o tempo, inseridas em cenários de conhecimento perito. Como exemplo, o autor menciona que, quando 
pessoas leigas embarcam em um avião, geralmente possuem pouco conhecimento a respeito da mecânica de funcionamento da aeronave, sendo a confiança na natureza do conhecimento perito o que faz com que, diariamente, milhões de sujeitos leigos embarquem em aeronaves, que se deslocam a centenas de quilômetros por hora. É nesse quadro que Giddens (1991) enfatiza que, diferentemente do que ocorre nas sociedades tradicionais, nas sociedades industriais, a confiança é mediada por peritos e especialistas, a partir de sistemas abstratos, uma vez que não há encontro entre os sujeitos ou grupos responsáveis por estes sistemas de conhecimento. Contudo, o autor alerta que os sistemas abstratos, construídos sob a égide de conhecimentos peritos, têm seguidamente sido confrontados pela modernidade reflexiva, posto que, nas últimas décadas, a ciência, responsável por criar muitas certezas, tem também sido fonte de desconfiança, em razão da produção de riscos advindos de novas tecnologias.

No campo da produção de alimentos, os sistemas abstratos de conhecimento se expressam no funcionamento da complexa cadeia da indústria agroalimentar global. Os consumidores urbanos têm, muitas vezes, uma noção bastante vaga sobre a origem e os processos de produção dos alimentos e, ainda assim - mesmo sem ter contato com os atores sociais envolvidos nessa produção
- depositam sua confiança no funcionamento do conhecimento perito referente à produção industrial de alimentos. Neste contexto, tornamse fundamentais os aparatos legais de fiscalização do Estado, bem como seus instrumentos, também simbólicos, como rótulos, carimbos e selos de qualidade, ferramentas desenvolvidas pelo Estado e pela indústria para avalizar a segurança e confiança nos processos de produção de alimentos.

Não obstante, Giddens (1991) também enfatiza que as interações face a face são cruciais, inclusive para os sistemas abstratos de confiança, visto que os pontos de acesso - locais em que os consumidores podem ter contato com representantes do sistema agroalimentar - são espaços vulneráveis, uma vez que o comportamento e as atitudes dos representantes do sistema podem reforçar ou destruir a confiança dos atores leigos no sistema de conhecimento perito. No entanto, em contextos de proximidade e informalidade, como os do Queijo Serrano e dos doces coloniais, aqui estudados, o "compromisso com rosto" parece, de fato, ser o "selo" que avaliza a qualidade e a confiança, dado que, nesses contextos, a própria reputação das famílias produtoras está todo o tempo sendo colocada em jogo.

Na sequência desta reflexão, vale trazer o estudo de Bailey (1971), o qual, ao observar o cotidiano de uma pequena aldeia nos Alpes franceses, buscou 
compreender os códigos morais que orientam a construção de reputações de sujeitos que convivem em um mesmo grupo social. $\mathrm{O}$ autor parte da noção de small politics para referir-se às ideias socialmente compartilhadas sobre como as pessoas são e/ou como elas supostamente deveriam atuar ou ser no interior do grupo social a que pertencem. Ele argumenta que, em pequenos grupos sociais, todos se conhecem ou, quando não se conhece todo mundo, ao menos não é difícil obter informações sobre outrem. Esse fundo comum de informações compartilhadas fornece o alicerce sobre o qual se constroem as reputações pessoais. Assim, Bailey (1971) argumenta que a reputação é fortemente dependente da proximidade e do grau de interação entre os sujeitos, ou seja, é especialmente na interação face a face que as reputações podem ser construídas ou destruídas. Na discussão proposta por Bailey (1971), a confiança, nesse tipo de sociedade, é entendida como extremamente vulnerável e, ao mesmo tempo, dependente da reputação construída na interação social.

É assim que, tanto nos Campos de Cima da Serra como em Pelotas, as famílias rurais são reconhecidas como detentoras de uma reputação, dada por sua expertise na produção de alimentos tradicionais, uma vez que guardam um saber-fazer que circula há gerações em suas famílias. Suas habilidades e competências são reconhecidas pelos consumidores, o que, a partir de um fundo comum de informações socialmente compartilhadas, os legitima como bons produtores. Não por acaso, a circulação informal de Queijo Serrano e de doces coloniais ocorre, frequentemente, em círculos muito próximos de parentesco, vizinhança e amizade das famílias produtoras, de modo que suas reputações são permanentemente testadas e atualizadas. Essa situação é muito bem expressa na declaração de Seu Matteus, um produtor de doces coloniais de Pelotas, reproduzida a seguir.

Eu tenho minha irmã e os meus sobrinhos que moram no [bairro] Fragata, em Pelotas, e aí cada dez ou quinze dias eu vou para Pelotas, então levo os doces para minha irmã e ela vende em casa, para conhecidos dela, vizinhos, familiares, assim. $\mathrm{Na}$ verdade, ela nem precisa sair de casa para vender, uma hora chega um e outra hora chega outro lá e ela oferece, e às vezes as pessoas vão lá só pra fazer encomenda pra ela, e então ela me liga e avisa: "oh, fulano tal quer isso, fulano tal pediu aquilo outro". $\mathrm{E}$ os filhos dela, os meus sobrinhos, trabalham assim em firma e aí eles oferecem pros colegas: "olha, meu tio faz doce bom da colônia”. Então assim, ela [irmã] faz isso pra me ajudar. Mas é assim, é de boca em boca, então o pessoal já me conhece, porque assim a gente consegue despachar quase tudo só entre conhecidos, amigos e parentes. Então a gente cuida pra fazer sempre com muito cuidado, higiene, né? Tudo limpinho, certinho, porque, enfim, são nossos amigos, e quase tudo era morador da colônia, então eles conhecem o produto, eles sabem a diferença de um doce ruim para um doce de qualidade. E outra, é o nome da gente, o meu rótulo é a minha cara, sem falar que é a minha irmã que vende, então é o nome da família, então a gente cuida sempre para fazer o melhor possível. E, graças a Deus, anos e anos e nunca tive uma queixa. 
Todos vivem em uma comunidade moral, na qual são compartilhados certos valores sociais, porém a reputação não é uma qualidade que nos pertença, não se pode construí-la sozinho, uma vez que, acima de tudo, é algo que pertence aos outros e que depende das opiniões de outras pessoas (Bailey 1971). Nesse sentido, é possível compreender as razões que levam o Sr. Matteus a enfatizar que o "rótulo" imaginário da sua produção doceira está associado ao nome da família. A preocupação de Matteus em oferecer produtos de qualidade está assentada no fato de que é o nome da família que é colocado em questão. Essa reputação - que parece incidir com muito mais força sobre o nome da família do que sobre as trajetórias individuais ${ }^{11}$ - depende, essencialmente, das opiniões dos consumidores, que, geralmente, fazem parte do círculo próximo de relações das famílias produtoras.

As entrevistas realizadas junto a famílias rurais das duas regiões estudadas atestam o fato de que, entre os principais consumidores de Queijo Serrano e de doces coloniais, estão ex-moradores da zona rural. Nesse sentido, vale salientar que, nas últimas décadas, o município de Caxias do Sul tem sido o principal polo de atração de moradores da região dos Campos de Cima da Serra, que buscam empregos nas indústrias desse município da Serra Gaúcha. Entretanto, a saída dos Campos de Cima da Serra em direção a Caxias do Sul não significou, para boa parte dos migrantes, o abandono de antigos laços de sociabilidade e parentesco com o meio rural. Dessa forma, muitos ex-moradores da região, ao retornarem a passeio, adquirem das famílias locais o Queijo Serrano, levando-o para seu consumo, mas também para presentear amigos e parentes que moram na cidade. É isso o que conta o Sr. Everton, produtor de queijo da região:

Nesses feriadão aí, tem muita gente de fora que vem passear na região e aproveita para passar nos sítios e comprar queijo. E tem também muito antigo morador, que hoje a maioria tá morando em Caxias, que quando vêm passear, sempre aproveita para levar o nosso queijinho Serrano. É gente que vem da cidade grande. Âs vezes, vem um ou outro passear aqui, juntam e vêm. Querem levar um queijo. É gente que acabou voltando e depois vai para lá e quer levar um queijo para os outros conhecidos da cidade grande.

11 Ao estudar práticas de parentesco entre agricultores teuto-brasileiros do Sul do Brasil, Ellen Woortmann (1995) já observara a importância da reputação entre grupos camponeses, em que aspectos positivos e negativos são atribuídos aos indivíduos de acordo com o Keim de cada família. A autora explica que o Keim é uma categoria nativa e está associada à ideia de que é transmitido hereditariamente, relacionando-se à reprodução e à observância de valores tradicionais. Nesse sentido, ela argumenta que o Keim representa o encontro do "como se deve ser" com o "como se é", e expressa "a realização exitosa das expectativas que o grupo possui acerca de determinadas famílias, através do controle social contínuo sobre os seus membros" (Woortmann 1995:142). Avaliam-se, portanto, as pessoas como derivadas de Keim ruim ou bom, ou seja, a partir de uma reputação herdada, porém baseada em valores centrais a uma ética camponesa. Desse modo, a pesquisa de E. Woortmann evidencia que Keim e reputação são valores coextensivos que funcionam como um patrimônio familiar comum, cujas qualidades positivas devem ser preservadas pelas futuras gerações. 
Como antes comentado, o mesmo se dá na região de Pelotas, onde ex-moradores da colônia, amigos e parentes próximos das famílias produtoras estão entre os consumidores de doces coloniais, participando de práticas de circulação do produto que se colocam à margem da rede de vigilância do Estado.

Portanto, parcela significativa dos consumidores de Queijo Serrano e de doces coloniais são sujeitos próximos, muitos deles ex-moradores da zona rural, que compartilham com as famílias rurais produtoras conhecimentos específicos para avaliar a qualidade dos produtos adquiridos. É possível, então, inferir que a reputação e a confiança nas famílias produtoras são construídas em diálogo com os hábitos alimentares dos consumidores, uma vez que é a partir desse conhecimento sustentado sobre a base de informações socialmente compartilhadas que são forjadas as reputações das famílias produtoras.

As famílias rurais têm clareza de que suas ações são fonte de construção de narrativas no interior da comunidade moral a que pertencem. Sabem, portanto, que suas reputações são permanentemente avaliadas, reforçadas ou refutadas. Ademais, como pontua Comerford (2003), em trabalho que analisa o tema da reputação entre famílias rurais de Minas Gerais, o deslocamento para a cidade de um membro de uma comunidade rural não significa necessariamente a ruptura do círculo social de julgamento, visto que as pessoas sabem onde seus familiares moram, o que fazem, fizeram ou deixaram de fazer. Fracassos e sucessos são conhecidos e comentados. No caso dos Campos de Cima da Serra e de Pelotas, isso é bem evidente, já que a mudança para a cidade não significa, para os migrantes, desligamento em relação a hábitos e à vida na zona rural. O trânsito de pessoas, produtos, julgamentos e reputações é constante entre a cidade e o meio rural. Nesse sentido, as famílias rurais sabem que seus consumidores urbanos mantêm contato com a vida na zona rural, sendo suas trajetórias familiares bem conhecidas por parte dos consumidores. Dessa forma, tornase fundamental para as famílias produtoras oferecer produtos feitos com cuidado, higiene e qualidade, uma vez que seus consumidores, além de possuírem habilidades específicas para julgar a qualidade dos produtos oferecidos, são sujeitos que também têm o poder de reforçar a confiança ou mesmo de destruir reputações no interior desse círculo de comercialização face a face.

É, portanto, possível concluir que, em contextos de proximidade, as informações socialmente produzidas e compartilhadas sobre a confiança e a reputação das famílias produtoras emergem como parâmetro para validar a qualidade de alimentos tradicionais. Desse modo, o status legal da produção 
alimentar requerida pelo Estado parece não ter muita importância em situações de proximidade, já que, em contextos onde predominam os circuitos curtos de circulação dos alimentos, a confiança é mediada, principalmente, por interações face a face entre produtores e consumidores. É assim que as evidências empíricas encontradas nos contextos analisados demonstram que as percepções e os critérios usados para julgar a qualidade dos produtos são construções culturais conformadas localmente, baseadas em relações de confiança e na reputação das famílias produtoras. Nessas circunstâncias, ainda que o Queijo Serrano e os doces coloniais não obedeçam a instrumentos convencionais de fiscalização, determinados pelo Estado, esses produtos seguem sendo demandados pelos consumidores, que se valem de mecanismos sociais de controle para validar a confiança e a qualidade dos produtos consumidos.

\section{CONSIDERAÇÕES FINAIS}

Neste artigo, tomamos como ponto de partida a observação das tendências da alimentação contemporânea, que indicam a existência de movimentos de valorização de produtos locais, artesanais, tradicionais. A busca crescente por alimentos com características associadas à produção local e de origem conhecida pode ser compreendida como uma resposta à crise de confiança na indústria agroalimentar, que, nas últimas décadas, tem seguidamente estado envolvida em escândalos de contaminação e adulteração de alimentos.

Temos, assim, que, no modo hegemônico de produção e abastecimento de alimentos em sociedades industrializadas, não baseado em relações de contato entre produtores e consumidores, a confiança é subvencionada pelo conhecimento de especialistas e institucionalizada a partir de um aparato de normas, leis, rótulos, carimbos, selos e certificados fornecidos pelo Estado ou por empresas privadas, que buscam garantir ao consumidor a origem, a qualidade e a segurança dos alimentos vendidos.

Mas a pesquisa aqui apresentada mostra que, em contextos de proximidade, como nos casos do Queijo Serrano dos Campos de Cima da Serra e dos doces coloniais de Pelotas, em que os produtos estão inseridos nos modos de vida tanto de produtores como de consumidores, as percepções a respeito da qualidade e da segurança dos produtos consumidos são influenciadas e estabelecidas, principalmente a partir de relações de confiança, marcadas pela convivência, face a face. Nessas circunstâncias, as informações compartilhadas sobre a confiança e a reputação dos produtores no interior de circuitos curtos de comercialização apresentam-se como mecanismos sociais de validação da qualidade 
dos alimentos. Desse modo, nessas relações face a face os parâmetros locais, socialmente construídos e compartilhados, se sobrepõem em relevância aos aparatos formais e legais estabelecidos pelo Estado, uma vez que ganham importância os laços de confiança estabelecidos nas relações de proximidade entre famílias produtoras e consumidores.

Cabe, por fim, enfatizar que este artigo não busca deslegitimar ou negar a importância das noções contemporâneas de higiene e qualidade na produção agroalimentar. Não obstante, buscamos evidenciar que existem formas tradicionais de produção ancoradas e ajustadas a critérios locais de qualidade e confiança, compartilhados por consumidores e produtores. Essas formas tradicionais de produzir, presentes em distintas realidades do rural brasileiro, estão articuladas a economias locais e a demandas de consumidores urbanos, cada vez mais interessados no acesso a alimentos tradicionais, artesanais, saudáveis e de origem conhecida. Por isso, cabe ao Estado o importante papel de assegurar a liberdade de escolha dos consumidores, promover a segurança alimentar, bem como garantir não apenas segurança jurídica, mas também dignidade e respeito aos modos de viver e de produzir alimentos que estão associados às tradições locais e à produção em pequena escala.

\section{AGRADECIMENTOS}

A presente pesquisa foi realizada com apoio da Coordenação de Aperfeiçoamento de Pessoal de Nível Superior (CAPES), código de financiamento 001.

\section{REFERÊNCIAS}

Bailey, F. G. 1971. Gifts and poison. Oxford: Blackwell.

Cintrão, R. P. 2016. Segurança, qualidade e riscos: a regulação sanitária e os processos de (i)legalização dos queijos artesanais de leite cru em Minas Gerais. Tese de Doutorado, Programa de Pós-Graduação de Ciências Sociais em Desenvolvimento, Agricultura e Sociedade, Universidade Federal Rural do Rio de Janeiro, Rio de Janeiro.

Comerford, J. C. 2003. Como uma família: sociabilidade, territórios de parentesco e sindicalismo rural. Rio de Janeiro: Relume Dumará.

Contreras, J. 2005. Patrimônio e globalização: o caso das culturas alimentares, in Antropologia e nutrição: 
um diálogo possível. Editado por A. Canesqui e R. W. D. Garcia, pp. 129-145. Rio de Janeiro: Fiocruz.

Contreras, J.; Gracia, M. 2011. Alimentação, sociedade e cultura. Rio de Janeiro: Editora Fiocruz.

Cruz, F. T. 2012. Produtores, consumidores e valorização de produtos tradicionais: um estudo sobre qualidade de alimentos a partir do caso do Queijo Serrano dos Campos de Cima da Serra - RS. Tese de Doutorado, Programa de Pós-Graduação em Desenvolvimento Rural, Universidade Federal do Rio Grande do Sul, Porto Alegre.

Cruz, F. T., E. E. Krone, e R. Menasche. 2014. "A gente vê comentar”: relações de proximidade e de confiança como certificadoras da qualidade do Queijo Serrano, in Anais do VII Encontro Nacional de Estudos do Consumo - ENEC. Rio de Janeiro: PUC-Rio.

Cruz, F. T., e R. Menasche. 2014. O debate em torno de queijos feitos de leite cru: entre aspectos normativos e a valorização da produção tradicional. Vigilância Sanitária em Debate: Sociedade, Ciência e Tecnologia 2(4):34-42. DOI: https://doi.org/10.3395/vd.v2i4.408.

Dias, J., M. Chiffoleau, R. P. Cintrão, V. Schottz, e J. Casemiro. 2018. Por normas sanitárias mais justas e inclusivas - em defesa da comida como patrimônio e da soberania e segurança alimentar e nutricional. Agriculturas 14(2):33-39.

Ferreira, E. G., e C. L. F. Ferreira. 2011. Implicações da madeira na identidade e segurança de queijos artesanais. Revista do Instituto de Laticínios Cândido Tostes 66(381):13-20.

Fischler, C. 1995. El (h)omnívoro: el gusto, la cocina y el cuerpo. Barcelona: Anagrama.

Fonseca, C. 2007. O anonimato e o texto antropológico: dilemas étnicos e políticos da etnografia 'em casa'. Teoria e Cultura 2(1):39-53. 
Friedmann, H., e P. Mcmichael. 1989. Agriculture and state system: the rise and decline of national agricultures, 1870 to the present. Sociologia Ruralis 29(2):93-117. DOI: https://doi. org/10.1111/j.1467-9523.1989.tb00360.x.

Geertz, C. 1989. A interpretação das culturas. Rio de Janeiro: LTC.

Giddens, A. 1991. As consequências da modernidade. São Paulo: Ed. UNESP.

Krone, E. E. 2006. Práticas e saberes em movimento: a história da produção artesanal do Queijo Serrano entre pecuaristas familiares do município de Bom Jesus (RS). Trabalho de Conclusão de Curso, Graduação em Desenvolvimento Rural e Gestão Agroindustrial, Universidade Estadual do Rio Grande do Sul, Encantado.

Krone, E. E. 2009. Identidade e cultura nos Campos de Cima da Serra (RS): práticas, saberes e modos de vida de pecuaristas familiares produtores do Queijo Serrano. Dissertação de Mestrado, Programa de Pós-Graduação em Desenvolvimento Rural, Universidade Federal do Rio Grande do Sul, Porto Alegre.

Krone, E. E. 2018. Da colônia ao sertão. Um estudo antropológico sobre os conflitos na construção da qualidade dos alimentos entre famílias rurais do Nordeste e do Rio Grande do Sul. Tese de Doutorado, Programa de Pós-Graduação em Antropologia, Universidade Federal de Pernambuco, Recife.

Lortal, S., A. Di Blassi, M. Madec, C. Pediliggieri, L. Tuminello, G. Tanguy, J. Fauquant, Y. Lecuona, P. Campo, S. Carpino, e G. Licitra. 2009. Tina wooden vat biofilm: a safe and highly efficient lactic acid bacteria delivering system in PDO Ragusano cheese making. International fournal of Food Microbiology 132(1):1-8. DOI: https://doi.org/10.1016/j.ijfoodmicro.2009.02.026.

Mintz, S. W. 1986. Sweetness and power: the place of sugar in modern history. New York: Elisabeth Sifton Books. 
Ploeg, J. D. V. D. 2008. Camponeses e impérios alimentares: lutas por autonomia e sustentabilidade na era da globalização. Porto Alegre: Editora UFRGS.

Portilho, F., e M. Castañeda. 2011. Certificação e confiança face a face em feiras de produtos orgânicos. Revista de Economia Agrícola 58(1):11-21.

Prigent-Simonin, A. H., e C. Hérault-Fournier. 2005. The role of trust in the perception of the quality of local food products: with particular reference to direct relationships between producer and consumer. Anthropology of Food (4). DOI: https://doi.org/10.4000/aof.204.

Santos, R. M. A., e M. R. F Gonçalves. 2010. Fábricas de doces coloniais de Pelotas (RS): entender o espaço para preservar seu patrimônio. Caderno do CEOM 1:103-120.

Schottz, V., R. S. Cintrão, e R. M. Santos. 2014. Convergências entre a Política Nacional de SAN e a construção de normas sanitárias para produtos da Agricultura Familiar. Vigilância Sanitária em Debate: Sociedade, Ciência e Tecnologia 2(4):115-123.

Wikipédia. 2019. Mesorregiões e microrregiões do Rio Grande do Sul. Flórida: Wikimedia Foundation. Disponível em: https://pt.wikipedia.org/w/index.php?title=Lista_de_mesorregi\%C3\%B5es_e_ microrregi\%C3\%B5es_do_Rio_Grande_do_Sul\&oldid=55808688. Acesso em: 23 jul. 2019.

Woortmann, E. F. 1995. Herdeiros, parentes e compadres: colonos do Sul e sitiantes do Nordeste. São Paulo: Hucitec. 